\title{
Finite Element Analysis on the Creep Constitutive Equation of High Modulus Asphalt Concrete
}

\author{
Xiu-shan Wang, ${ }^{1}$ Tao-tao Fan, ${ }^{1}$ and Lum Kitmeng ${ }^{2}$ \\ ${ }^{1}$ School of Civil Engineering and Architecture, Zhejiang Sci-Tech University, Hangzhou 310018, China \\ ${ }^{2}$ College of Environmental and Civil Engineering, Nanyang Technological University, Block Ni, Nanyang Avenue, Singapore 639798 \\ Correspondence should be addressed to Xiu-shan Wang; wxs77777@163.com
}

Received 8 April 2015; Revised 25 June 2015; Accepted 6 July 2015

Academic Editor: Ana S. Guimarães

Copyright (c) 2015 Xiu-shan Wang et al. This is an open access article distributed under the Creative Commons Attribution License, which permits unrestricted use, distribution, and reproduction in any medium, provided the original work is properly cited.

\begin{abstract}
In order to obtain the viscoelastic constitutive relation of High Modulus Asphalt Concrete (HMAC), the constitutive relationship is used to carry on the various numerical calculation, utilize integral transforming in its Bailey-Norton creep rule, and establish new practical model. Combining with the collection data from creep tests of uniaxial compression, regression calculation is carried out with 1STOPT fitting software; thus the creep parameters of High Modulus Asphalt Concrete in different temperatures were obtained, which can be used in HMAC creep model.
\end{abstract}

\section{Introduction}

High Modulus Asphalt Concrete (HMAC) is originally a kind of asphalt concrete mixture agitated by hard asphalt, a certain grading of stone, and additives. Under $15^{\circ} \mathrm{C}, 10 \mathrm{~Hz}$ test conditions, its dynamic modulus can reach over $14000 \mathrm{MPa}$ [1-6], which fully exhibited such advantages as high modulus, good rutting resistance, low temperature cracking, and low thermal fatigue cracking sensitivity. As the viscoelastic material, HMAC has unique constitutive relation different from other elastic, elastic-plastic materials; thus it is more difficult to grasp its mechanical characteristics. However, the development of viscoelastic theory provides mechanical analysis of HMAC with an effective tool finite element method. Since there is no complex analytic derivation in the finite element method, it is convenient to simulate viscoelastic of road materials and analyze the actual stress state of road surface [7-11].

Due to the simplicity and high controllability of creep test method, many researchers have conducted a lot of laboratory tests to reveal the actual stress condition of road surface through the asphalt concrete material stress-strain relationship. But it is still very difficult to obtain viscoelastic parameters from these asphalt stress-strain data and then use computer software to simulate its mechanical characteristics.
There are two reasons: one is the low precision degree of data fitting; the other is the inconsistency of formula in data fitting and computer simulation software. Therefore, though many researchers have viscoelastic data, they adopt elastic or elastic-plastic method instead to calculate the stress state of the approaching road surface $[12,13]$. In order to better utilize these data, this paper analyzed the creep model in ABAQUS suitable for high modulus asphalt and carried on integration processing on Bailey-Norton creep law to establish new practical model. Based on the numerical simulation of uniaxial compression creep test, the creep parameters of High Modulus Asphalt Concrete in different temperatures were obtained by regression calculation with software 1STOPT of high efficiency and user-friendly control.

\section{The Creep Constitutive Equations of Asphalt Concrete}

The finite element analysis on material nonlinear problem has two aspects, namely, the establishment of the constitutive formula and the solution to nonlinear equations. Material constitutive relations are usually divided into two categories: the full amount of the constitutive equations and the incremental constitutive equations. Since the plastic deformation 
is unrecoverable inelastic deformation, stress state cannot be determined by the current state of deformation but rather by the route and deformation history. To accommodate this situation, the incremental constitutive equations are usually adopted in finite element analysis.

Generally, creep effect is time-dependent; that is, under constant load conditions, the deformation of material increases with time. With constant load and displacement, creep effect has two stages: redistribution of stress within the structure as the first stage and the steady stress state of the structure as the second. In the process from transient creep state to steady creep state, the first stage is named as transient creep stage and the second stage is named as steady state creep stage. The steady creep stage can be analyzed by the full amount of the finite element analysis. But, for the transient creep, the load of a given change over time, and the structural creep effect under displacement, an incremental finite element method analysis is used usually along with thermal elastic-plastic incremental analysis, known as thermal elasticplastic creep analysis.

Asphalt concrete, which is the material dependent on time, temperature, and stress, presents deformation response in elasticity, plasticity, viscoelasticity, and viscoplasticity under repeated loads. The strain parameters can be expressed as

$$
\varepsilon=\varepsilon_{\mathrm{e}}+\varepsilon_{\mathrm{p}}+\varepsilon_{\mathrm{ve}}+\varepsilon_{\mathrm{vp}} .
$$

In (1), $\varepsilon$ is the total strain varying with time, $\varepsilon_{\mathrm{e}}$ is elastic strain (recoverable and independent of time), $\varepsilon_{\mathrm{p}}$ is plastic strain (unrecoverable and independent of time), $\varepsilon_{\mathrm{ve}}$ is viscoelastic strain (recoverable and time-dependent), and $\varepsilon_{\mathrm{vp}}$ is viscoplastic strain (unrecoverable and time-dependent).

Obviously, such plastic nature of the asphalt mixture as plastic strain and viscoplastic strain can generate permanent deformation, and those plastic strains are cumulative under repeated loads. So only viscoplastic strain remains to be calculated. However, it is very hard to differentiate viscoelastic part and viscoplastic part especially when the two are changeable under repeated loads. On the other hand, creep tests can easily identify elastic strain and inelastic strain, that is, creep strain, which should include viscoplastic strain and a part of viscoelastic strain at a certain point of time. Since the current test method can only measure the combined effects of the two, creep and plasticity cannot be treated respectively.

The creep deformation of the material can be expressed as a function of temperature $T$, stress $\sigma$, and time $t$; that is, $\varepsilon_{\mathrm{c}}=f(T, \sigma, t)$ which can be used to analyze the creep deformation [14-17]. Therefore, Bailey-Norton creep model in ABAQUS can be used to simulate the nonlinearity of the asphalt concrete layer. Equation (2) is expressed in the form of creep strain rate, as follows:

$$
\varepsilon_{\mathrm{cr}}=C_{1} \sigma^{C_{2}} t^{C_{3}} e^{-C_{4} / T} .
$$

In (2), $\varepsilon_{\text {cr }}$ is creep strain rate; $e$ is 2.718 ; $t$ is time; $T$ is temperature; $C_{1}, C_{2}, C_{3}$, and $C_{4}$ are material parameters.

In order to simplify the model and enhance its usability, the Bailey-Norton creep law was retransformed by carrying
TABLE 1: The optimum asphalt content.

\begin{tabular}{lccccc}
\hline Mixture type & $50 \#-1$ & $50 \#-2$ & $70 \#-1$ & $70 \#-2$ & $70 \#-3$ \\
\hline Best oilstone ratio & 4.1 & 4.4 & 4.0 & 4.1 & 4.3 \\
\hline
\end{tabular}

on integral calculation on both sides simultaneously. The results are as follows:

$$
\int_{\varepsilon_{\mathrm{c}}}^{\varepsilon_{\mathrm{cr}}} d \varepsilon_{\mathrm{cr}}=\int_{0}^{t} C_{1} \sigma^{C_{2}} t^{C_{3}} e^{-C_{4} / T} d t
$$

When the temperature is constant, $C_{4}=0$, and (3) can be converted into

$$
\varepsilon_{\mathrm{cr}}=\frac{C_{1} \sigma^{C_{2}} t^{C_{3}+1}}{C_{3}+1}
$$

Equation (4) is the time hardening creep model (expressed by creep rate) in the converted ABAQUS; $C_{1}, C_{2}, C_{3}$ are model parameters dependent on temperature, which can be determined by material testing.

\section{Creep Tests on High Modulus Asphalt Concrete}

Since the High Modulus Asphalt Concrete is mainly used in sections of large traffic volume and harsh stress environment, grade A asphalt in specification [18] was chosen as asphalt material in the High Modulus Asphalt Concrete. In this study, two kinds of asphalt 50\# and 70\#, respectively, from Zhonghai Company were chosen based on the market survey, and five kinds of asphalt 70\#-1 with additive from French PR company were chosen according to its mixed recommended dosage. They are 50\#-1, 50\#-2, 70\#-1, 70\#-2, and 70\#-3. The performances of them can all meet the norms. The optimum asphalt content is shown in Table 1. Aggregate grading was selected from specification AC-20 median grading and the grading composition is shown in Table 2.

Use MTS810 material testing machine imported from America to conduct the test with uniaxial compression creep method. The specimen size was $100 \mathrm{~mm}$ in diameter, its height was $100 \mathrm{~mm}$, and test temperature was $20^{\circ} \mathrm{C}, 40^{\circ} \mathrm{C}$, and $60^{\circ} \mathrm{C}$, respectively. A series of pressure $(0.1 \mathrm{MPa}, 0.2 \mathrm{MPa}, 0.3 \mathrm{MPa}$, $0.4 \mathrm{MPa}$, and $0.5 \mathrm{MPa}$ ) was loaded on the specimen for 60 minutes and then unloaded for 10 minutes before starting processing data. Through these tests, the changes of vertical accumulative strain over time for specimens of different type produced at different temperatures during creep process were obtained. Due to space limitations, only two graphs are presented here with Figure 1 showing creep curves for different types of asphalt mixture at temperature $40^{\circ} \mathrm{C}$ and Figure 2 showing the creep curves of 70\#-1 asphalt mixture at different temperatures.

From Figure 1, it can be seen that, at loading stage, the instantaneous deformation of the specimen first occurs under the initial load, and then, with continuing role of dead load, the specimen deformation keeps increasing until the deformation increments are steady. After unloading, the elastic deformation resumes immediately, viscoelastic deformation gradually recovers over time, and plastic deformation 
TABLE 2: Grading composition in AC-20 median asphalt concrete.

\begin{tabular}{lccccccccccccc}
\hline $\begin{array}{l}\text { Sieve size } \\
\text { grading composition }\end{array}$ & \multicolumn{10}{c}{ Pass rate of hole sieve (\%) } \\
& 31.5 & 26.5 & 19 & 16 & 13.2 & 9.5 & 4.75 & 2.36 & 1.18 & 0.6 & 0.3 & 0.15 & 0.075 \\
\hline AC-20 & 100 & 100 & 95 & 85 & 71 & 61 & 41 & 30 & 22.5 & 16 & 11 & 8.5 & 5 \\
\hline
\end{tabular}

TABLE 3: Creep parameters for asphalt concrete.

\begin{tabular}{|c|c|c|c|c|c|c|c|c|c|}
\hline \multirow{3}{*}{ Mixture type } & \multicolumn{9}{|c|}{ Creep parameters } \\
\hline & \multicolumn{3}{|c|}{$C_{1}$} & \multicolumn{3}{|c|}{$\mathrm{C}_{2}$} & \multicolumn{3}{|c|}{$C_{3}$} \\
\hline & $20^{\circ} \mathrm{C}$ & $40^{\circ} \mathrm{C}$ & $60^{\circ} \mathrm{C}$ & $20^{\circ} \mathrm{C}$ & $40^{\circ} \mathrm{C}$ & $60^{\circ} \mathrm{C}$ & $20^{\circ} \mathrm{C}$ & $40^{\circ} \mathrm{C}$ & $60^{\circ} \mathrm{C}$ \\
\hline $50 \#-1$ & $2.98 e-15$ & $1.06 e-16$ & $1.85 e-21$ & 2.815 & 3.101 & 3.860 & -0.809 & -0.820 & -0.914 \\
\hline $50 \#-2$ & $6.23 e-16$ & $2.22 e-17$ & $1.27 e-22$ & 1.808 & 2.369 & 2.898 & -0.646 & -0.696 & -0.631 \\
\hline $70 \#-1$ & $8.67 e-16$ & $3.09 e-17$ & $5.39 e-22$ & 2.026 & 2.655 & 3.248 & -0.690 & -0.712 & -0.670 \\
\hline $70 \#-2$ & $6.52 e-16$ & $2.33 e-17$ & $4.06 e-22$ & 1.921 & 2.305 & 2.469 & -0.690 & -0.663 & -0.670 \\
\hline $70 \#-3$ & $1.26 e-6$ & $1.66 e-7$ & $1.87 e-8$ & 0.378 & 0.517 & 0.565 & -0.820 & -0.875 & -0.720 \\
\hline
\end{tabular}

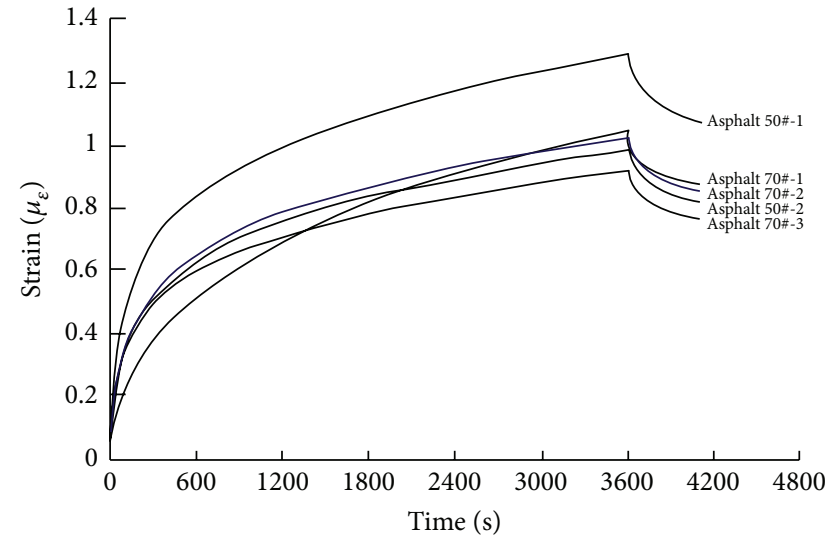

FIGURE 1: Creep curves for different types of asphalt mixture.

remains deformed permanently because of its irreversibility. Asphalt mixtures present the following rule according to their cumulative creep strains: $70 \#-3<50 \#-2<70 \#-2<70 \#-$ $1<50 \#-1$. The cumulative strain of asphalt concrete $50 \#-1$ is the maximum, indicating its weakest capacity to resist deformation under sustained loads; concrete 70\#-3, mixed with $0.7 \%$ additive, has the minimum cumulative strain, indicating its strongest capacity to resist high temperature deformation.

From Figure 2, it can be seen that, under the same stress conditions, as the temperature increases, both the accumulated deformation and the residual deformation after relaxation are increased. At the high temperature of $40^{\circ} \mathrm{C}$ and $60^{\circ} \mathrm{C}$, instantaneous deformation of High Modulus Asphalt Concrete with $0.7 \%$ additive is consistent with the ordinary asphalt concrete, while the cumulative deformation of the former is far less than the latter with the growth of loading time, indicating a significant improvement in high temperature deformation assistance of the asphalt mixture with admixture.

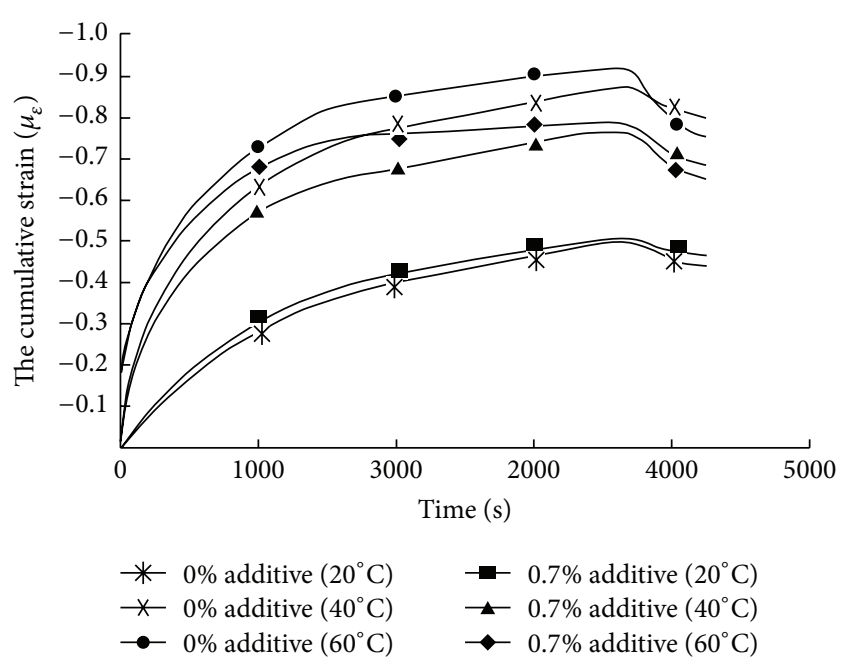

FiguRE 2: Creep curves of 70\#-1 asphalt at different temperatures.

\section{Creep Model Parameters Results}

According to the creep performance test results of High Modulus Asphalt Concrete under different temperature conditions as well as treatment and regression conducted by professional fitting software 1STOPT, creep parameters $C_{1}$, $\mathrm{C}_{2}$, and $\mathrm{C}_{3}$ of 5 different types of asphalt concrete are obtained, respectively, as shown in Table 3.

From Table 3, the following can be seen.

At the same temperature, creep model coefficient $C_{1}$ has the biggest amplitude of variation and exhibits the change in the order of magnitudes with additive, while partial stress index $C_{2}$ is reduced in five asphalt concrete creep parameters of different types. Time index $C_{3}$ is always negative, its absolute value being less than 1 , and changes little with additive variation.

As for creep parameters at different temperatures, whatever the material is, the amplitude of variation in the creep model coefficient $C_{1}$ is always the biggest with the series of 
change in the gap, and the higher the temperature is, the smaller the value of $C_{1}$ is. As for partial stress index $C_{2}$, its value increases along with the temperature increase. The time index $C_{3}$, always being -1 and 0 , shows no significant change regardless of temperature change.

At different temperatures, compared with the other four mixtures, the creep coefficient model $C_{1}$ of High Modulus Asphalt Concrete (70\#-3) shows increases in series, while the partial stress index $C_{2}$ decreases by 4 to 6 times.

\section{Conclusions}

(1) By integration process of the time hardening creep model in ABAQUS, a new simplified creep model is established.

(2) From laboratory High Modulus Asphalt Concrete creep test, it can be learned that the size of creep accumulative strain of asphalt mixtures shows the following rule: $70 \#-3<50 \#-2<70 \#-2<70 \#-1<50 \#-1$. Among all the five types, high modulus asphalt mixture with added additive shows the strongest high temperature deformation resistance.

(3) Creep parameters of different types of High Modulus Asphalt Concrete at different temperatures are obtained with the professional fitting software 1STOPT on the basis of numerical simulation of uniaxial compression creep test.

\section{Conflict of Interests}

The authors declare that there is no conflict of interests regarding the publication of this paper.

\section{Acknowledgments}

The authors gratefully acknowledge the financial support from research funds of Zhejiang Sci-Tech University (no. 1205826-Y) and the Transverse fund (nos. 13050421-J and 14050156-J).

\section{References}

[1] J.-F. Corté, "Development and uses of hard-grade asphalt and of high-modulus asphalt mixes in france," in Proceedings of the Transportation Research Board, pp. 12-31, Washington, DC, USA, December 2001.

[2] J. Cheng and X. Qian, "Temperature-dependent viscoelastic model for asphalt concrete using discrete rheological representation," Construction and Building Materials, vol. 93, pp. 157-165, 2015.

[3] Q. Zhou, A. Sha, and Q. Yang, "Experimental study on mechanical properties of high modulus asphalt concrete," Journal of Zhengzhou University: Engineering Science, vol. 29, no. 1, pp. 128-131, 2008.

[4] J. Chen, M. Zhang, H. Wang, and L. Li, "Evaluation of thermal conductivity of asphalt concrete with heterogeneous microstructure," Applied Thermal Engineering, vol. 84, pp. 368-374, 2015.
[5] S. M. J. G. Erkens, X. Liu, and A. Scarpas, "3D finite element model for asphalt concrete response simulation," International Journal of Geomechanics, vol. 2, no. 3, pp. 305-330, 2002.

[6] J. Chen, C. Zhou, and Z. Wang, "Data processing and viscoelastic computation for creep test of asphalt mixture," Journal of Southeast University (Natural Science Edition), vol. 37, no. 6, pp. 1091-1095, 2007.

[7] V. Subramanian, M. N. Guddati, and Y. Richard Kim, "A viscoplastic model for rate-dependent hardening for asphalt concrete in compression," Mechanics of Materials, vol. 59, pp. 142159, 2013.

[8] K. Hibbitte, ABAQUS User Subroutines Reference Manual, HKS, Dallas, Tex, USA, 2005.

[9] Ministry of Transportation of People's Republic of China, "Highway asphalt pavement construction technology specifications," Tech. Rep. JTG F98-140, China Communications Press, Beijing, China, 2004.

[10] M. F. Granata, P. Margiotta, and M. Arici, "Simplified procedure for evaluating the effects of creep and shrinkage on prestressed concrete girder bridges and the application of European and north American prediction models," Journal of Bridge Engineering, vol. 18, no. 12, pp. 1281-1297, 2013.

[11] T. B. Moghaddam, M. Soltani, and M. R. Karim, "Evaluation of permanent deformation characteristics of unmodified and Polyethylene Terephthalate modified asphalt mixtures using dynamic creep test," Materials \& Design, vol. 53, pp. 317-324, 2014.

[12] A. Mehmanparast, C. M. Davies, G. A. Webster, and K. M. Nikbin, "Creep crack growth rate predictions in $316 \mathrm{H}$ steel using stress dependent creep ductility," Materials at High Temperatures, vol. 31, no. 1, pp. 84-94, 2014.

[13] J. Ganesh Kumar and M. D. Mathew, "Finite element analysis of plastic deformation during impression creep," Journal of Materials Engineering and Performance, vol. 24, no. 4, pp. 17411753, 2015.

[14] E. Coleri, J. T. Harvey, K. Yang, and J. M. Boone, "Development of a micromechanical finite element model from computed tomography images for shear modulus simulation of asphalt mixtures," Construction and Building Materials, vol. 30, pp. 783793, 2012.

[15] G. Harran and A. Shalaby, "Improving the prediction of the dynamic modulus of fine-graded asphalt concrete mixtures at high temperatures," Canadian Journal of Civil Engineering, vol. 36, no. 2, pp. 180-190, 2009.

[16] M. Espersson, "Effect in the high modulus asphalt concrete with the temperature," Construction and Building Materials, vol. 71, pp. 638-643, 2014.

[17] S. S. Yakovlev, S. N. Larin, Y. A. Sobolev, and V. I. Platonov, "Isothermal deformation of dome-shaped shells made of highstrength anisotropic materials in the presence of creep," Russian Engineering Research, vol. 35, no. 2, pp. 116-120, 2015.

[18] X.-Y. Zhu, X. Wang, and Y. Yu, "Micromechanical creep models for asphalt-based multi-phase particle-reinforced composites with viscoelastic imperfect interface," International Journal of Engineering Science, vol. 76, pp. 34-46, 2014. 

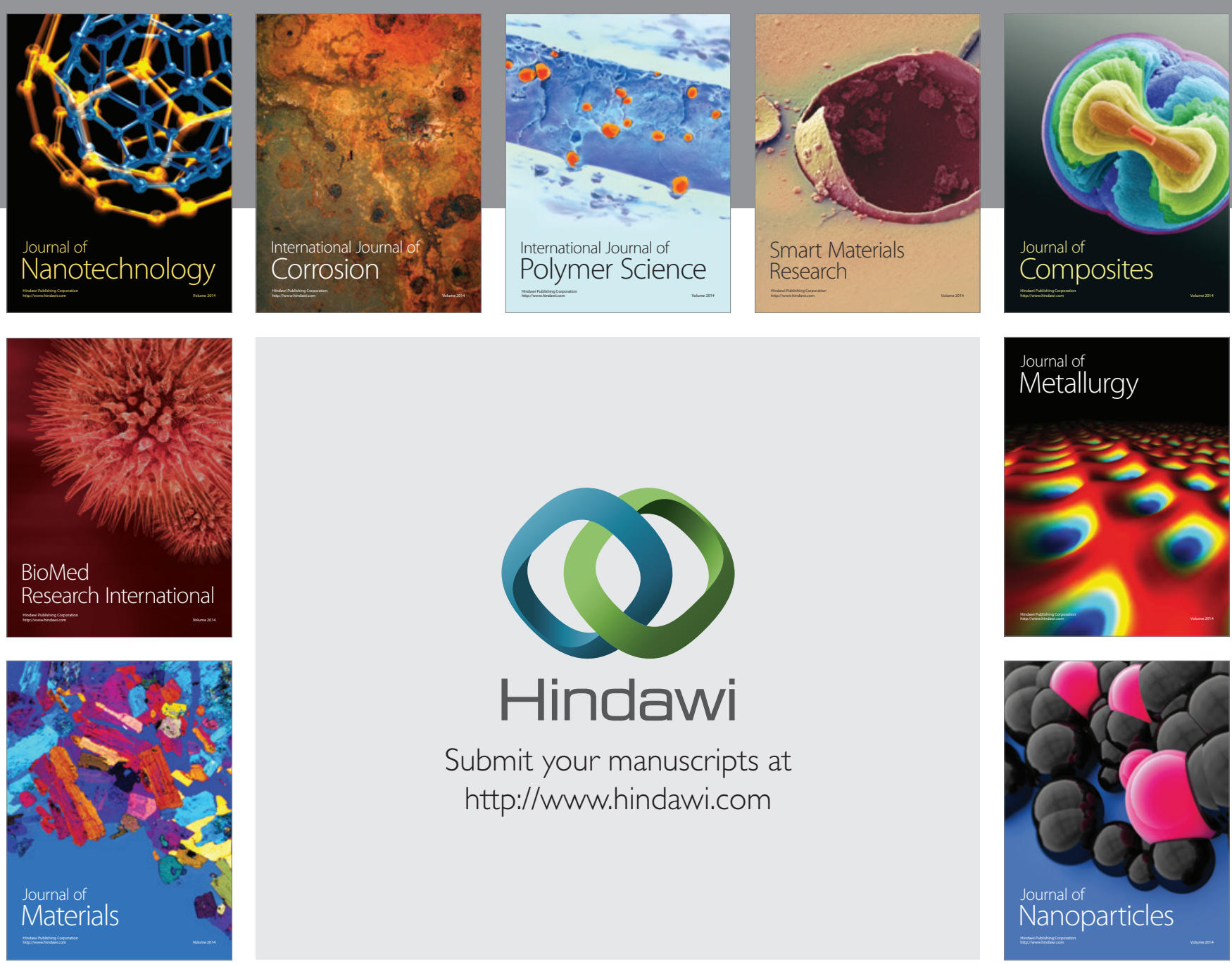

Submit your manuscripts at http://www.hindawi.com
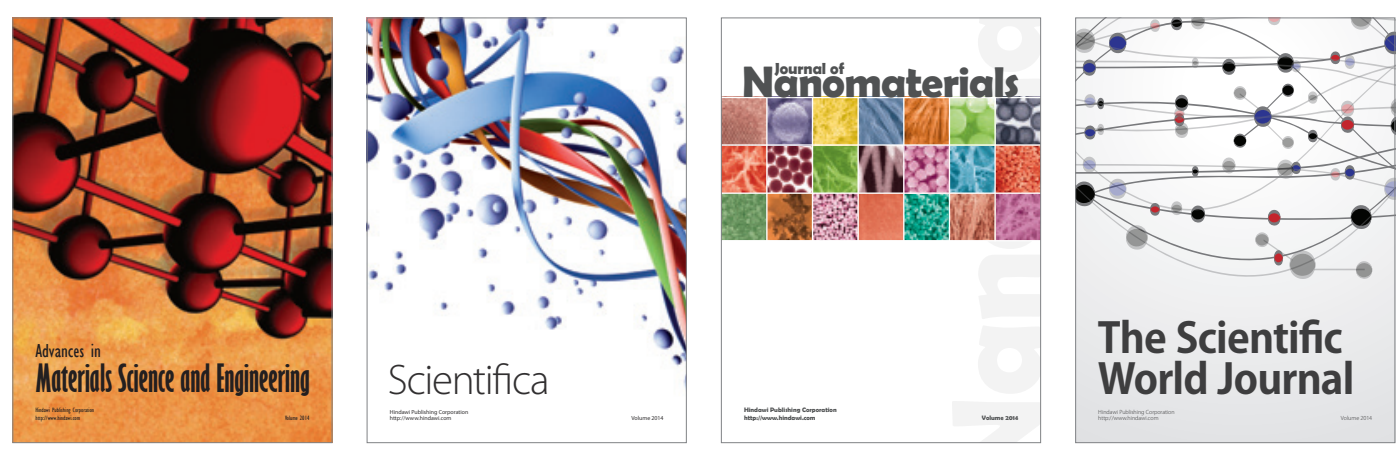

\section{The Scientific World Journal}
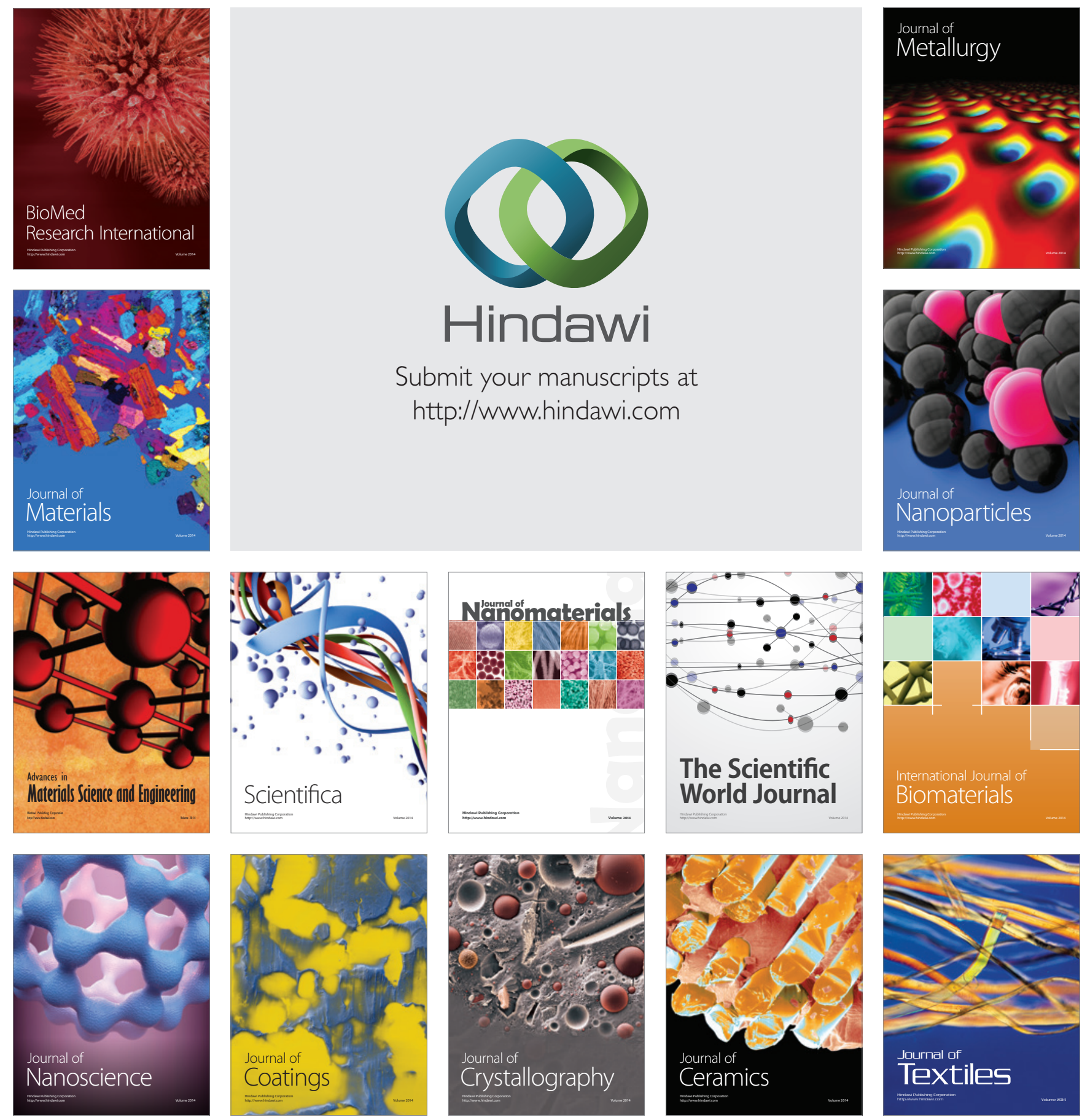